\section{IMPACT OF DYNAMIC CAPABILITIES ON SMALL AND MEDIUM ENTERPRISES PERFORMANCE IN A VOLATILE ENVIRONMENT AS MODERATED BY ORGANIZATIONAL INERTIA}

\author{
JeyaranjanPrasheenaa \\ Temporary Assistant Lecturer, Department of Management, Eastern University Sri Lanka. \\ prashcre@gmail.com \\ and \\ Mrs. D. Thavakumar \\ Senior Lecturer, Department of Management, Eastern University Sri Lanka. \\ Dila1981@gmail.com
}

\begin{abstract}
In Sri Lanka especially in Batticaloa, the studies related to dynamic capabilities, organizational inertia and organizational performance are rare and there is need to fill this empirical gap by investigating the influence of the dynamic capabilities of small and medium enterprises (SMEs) on organizational performance, and the interaction between dynamic capabilities and organizational inertia in a volatile environment. Therefore, this study has been undertaken to examine the relationship among these three variables and to assess the moderating role of organizational inertia in relationship between dynamic capabilities and organizational performance. The findings indicated that the variables have significant relationships among them and further findings of this study revealed that organizational inertia negatively moderates the relationship between dynamic capabilities and organizational performance of SMEs in Manmunai North Divisional Secretariat in Batticaloa District.

By addressing the findings of this study SME owners could try to reduce the inertia in their business by which the relationship between dynamic capabilities and performance can be induced and this lead the businesses in achieving competitive advantages.
\end{abstract}

Keywords: Small and Medium Enterprises, Dynamic Capabilities, Sensing Capabilities, Organizational Performance, Organizational Inertia.

\section{Introduction}

In today's markets, there are so many environmental turbulences which the marketers are facing that arises from technological advances, changes in consumer demand, and new regulations (Helfat\& Winter, 2011). These developments can impact on organizational performance and also cause a decline in the competitive advantages of the firms or to even become redundant. According to Zott (2003), some firms have the ability to deal better with environmental turbulence than others and that it is of interest to identify the factors that cause performance differentials when responding to environmental turbulence. In general, performance differentials have either been attributed to the industry or to the organization itself (Schmalensee, 1985). Dynamic capabilities are expected to be valuable for organizations when dealing with environmental turbulence (Teece, Pisano \&Shuen, 1997). Researches have shown that dynamic capabilities have both direct and indirect effects on organizational performance: directly via dynamic capability

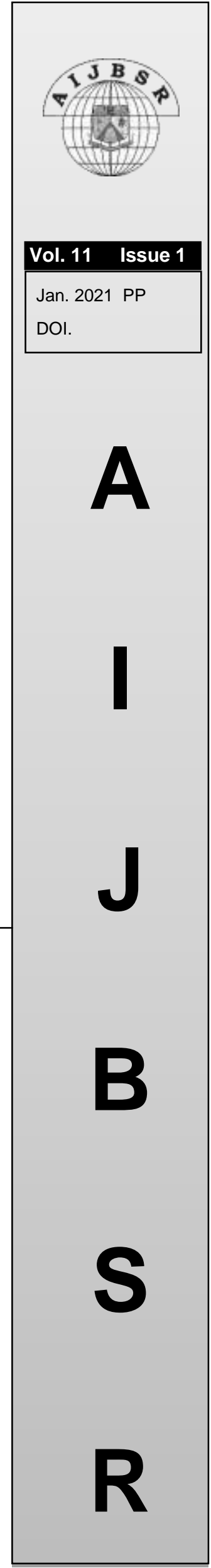

